\title{
Interleukin-29 Enhances Synovial Inflammation and Cartilage Degradation in Osteoarthritis
}

\author{
Lingxiao Xu, ${ }^{1}$ Qiuyue Peng, ${ }^{2}$ Wenhua Xuan, ${ }^{1}$ Xiaoke Feng, ${ }^{2}$ Xiangqing Kong, \\ Miaojia Zhang, ${ }^{1}$ Wenfeng Tan, ${ }^{1}$ Meilang Xue, ${ }^{4}$ and Fang Wang ${ }^{3}$ \\ ${ }^{1}$ Department of Rheumatology, The First Affiliated Hospital of Nanjing Medical University, Nanjing 210029, China \\ ${ }^{2}$ Department of Traditional Chinese Medicine, The First Affiliated Hospital of Nanjing Medical University, \\ Nanjing 210029, China \\ ${ }^{3}$ Department of Cardiology, The First Affiliated Hospital of Nanjing Medical University, Nanjing 210029, China \\ ${ }^{4}$ Sutton Arthritis Research Laboratories, University of Sydney at Royal North Shore Hospital, Sydney, NSW, Australia
}

Correspondence should be addressed to Fang Wang; fangwang7608@263.net

Received 8 April 2016; Revised 23 May 2016; Accepted 29 May 2016

Academic Editor: Anshu Agrawal

Copyright (C) 2016 Lingxiao Xu et al. This is an open access article distributed under the Creative Commons Attribution License, which permits unrestricted use, distribution, and reproduction in any medium, provided the original work is properly cited.

We have recently shown that IL-29 was an important proinflammatory cytokine in pathogenesis of rheumatoid arthritis (RA). Inflammation also contributes to the pathogenesis of osteoarthritis (OA). The aim of this study was to investigate the effect and mechanism of IL-29 on cytokine production and cartilage degradation in OA. The mRNA levels of IL-29 and its specific receptor IL-28Ra in peripheral blood mononuclear cells (PBMCs) were significantly increased in OA patients when compared to healthy controls (HC). In the serum, IL-29 protein levels were higher in OA patients than those in HC. Immunohistochemistry revealed that both IL-29 and IL-28Ra were dramatically elevated in OA synovium compared to HC; synovial fibroblasts (FLS) and macrophages were the main IL-29-producing cells in OA synovium. Furthermore, recombinant IL-29 augmented the mRNA expression of IL$1 \beta$, IL-6, IL-8, and matrix-metalloproteinase-3 (MMP-3) in OA FLS and increased cartilage degradation when ex vivo OA cartilage explant was coincubated with OA FLS. Finally, in OA FLS, IL-29 dominantly activated MAPK and nuclear factor- $\kappa \mathrm{B}$ (NF- $\kappa \mathrm{B})$, but not Jak-STAT and AKT signaling pathway as examined by western blot. In conclusion, IL-29 stimulates inflammation and cartilage degradation by OA FLS, indicating that this cytokine is likely involved in the pathogenesis of OA.

\section{Introduction}

Interleukin-29 (IL-29) is the main cytokine among three members of interferon lambda family (IFN- $\lambda$ s), also known as type III IFNs, including IFN- $\lambda 1$, IFN- $\lambda 2$, and IFN- $\lambda 3$ (or IL-29, IL-28A, and IL-28B, resp.). The activity of IL-29 is determined in part by the distribution and expression of its specific IL-28 receptor alpha chain (IL-28Ra). IL-28Ra is widely expressed by ranges of cells including epithelial cells, hepatocytes, fibroblasts [1,2], and immune cells, such as plasmacytoid DCs, macrophages, Th17 cells, and NK cells [36]. The most studied biological role of IFN- $\lambda \mathrm{s}$ is its antiviral activity, but recent investigation starts to uncover a unique role of IFN- $\lambda \mathrm{s}$ in and beyond innate antiviral immunity $[4,7]$. IL-29 can induce antiproliferative and antitumor properties $[8,9]$, inhibit IL-13 release in T cells [1], and stimulate IL-6,
IL-8, and IL-10 production in macrophages [2] and IL-4 and IL-13 in mast cells [10]. A recent study showed that IL-29 is able to indirectly affect NK cells by regulating IL12 in macrophages [6]. Moreover, our recent studies have demonstrated that IL-29 levels are higher in peripheral blood mononuclear cells (PBMCs) and serum and synovium from rheumatoid arthritis (RA) patients when compared to healthy individuals [1]. Recombinant IL-29 enhances IL-6, IL-8, and matrix-metalloproteinases (MMPs) production in RA fibroblasts and promotes RA inflammation [1]. IL-29 has also been shown to contribute to other immune diseases, such as systemic lupus erythematosus (SLE) [11, 12], asthma [3], and psoriasis [5]. However, the role of IL-29 in inflammatory diseases remains largely unexplored and whether IL29 is involved in the pathogenesis of osteoarthritis (OA) is unclear. 
$\mathrm{OA}$ is one of the most common disorders and has traditionally been classified as a noninflammatory arthritis; however, increasing evidence shows that synovitis and the immune system are also active players in OA development and progression [4]. For examples, OA synovial fibroblasts (FLS) contribute to OA pathogenesis by producing inflammatory cytokines such as tumor necrosis factor- $\alpha$ (TNF- $\alpha$ ), IL- $1 \beta$, and chondrolytic mediators such as MMPs [5]; FLSderived IL-1 $\beta$ and TNF- $\alpha$ induce cartilage degradation [13]. In addition, FLS can mediate the innate immune response by responding to both inflammatory cytokines and Tolllike receptor (TLR) ligands [14]. We have shown that IL-29 enhanced RA inflammation and mediated TLR activation in RA FLS [1, 2]. OA and RA share some similarities in pathogenesis, such as chronic inflammation, synovial hyperplasia, articular destruction, and abnormal immune response. We therefore hypothesize that IL-29 contributes to OA pathogenesis. To address this issue, we examined the potential role of IL-29 as a proinflammatory cytokine in OA disease.

This study, for the first time, showed that IL-29 was higher in blood and synovium from OA patients when compared with healthy controls (HC). Recombinant IL-29 increased the expression of proinflammatory cytokine in OA FLS in vitro and promoted cartilage degradation in coculture of OA FLS and cartilage explant ex vivo. Finally, our studies revealed that the effect of IL-29 on OA FLS was likely mediated by NF- $\kappa$ B and MAPK signaling pathway. Our present data support the hypothesis that IL-29 may contribute to synovial inflammation and cartilage degradation in OA.

\section{Materials and Methods}

2.1. Reagents. Recombinant human IL-29 and IL-1 $\beta$ were purchased from Peprotech (Rocky Hill, NJ, USA); rabbit anti-human IL-29/IL-28R $\alpha$ polyclonal antibody and mouse anti-human CD68 monoclonal antibody were purchased from Abcam (Cambridge, MA, USA); mouse anti-human fibroblast growth factor-basic (FGF-2) monoclonal antibody was purchased from Millipore (Billerica, MA, USA); PE antihuman IL-28R $\alpha$ was purchased from BioLegend (San Diego, CA, USA); donkey anti-rabbit IgG-R and goat anti-rabbit IgG/TRITC were purchased from Santa Cruz Biotechnology (Santa Cruz, CA, USA); DyLight ${ }^{\mathrm{TM}} 488$-conjugated AffiniPure donkey anti-mouse IgG, peroxidase-conjugated sheep antirabbit secondary antibody, and peroxidase-conjugated sheep anti-mouse secondary antibody were purchased from Jackson Immunoresearch (West Grove, PA, USA); human IL-29 antibody was purchased from R\&D Systems (Minneapolis, MN, USA); human IL-29 enzyme-linked immunosorbent assay (ELISA) reagent kits were purchased from Adlitteram Diagnostic Laboratories (San Diego, CA, USA); MMP-3 ELISA kit was purchased from USCN Life Science Inc. (Wuhan, China); Safranin O staining kit was purchased from ScienCell Research Laboratories (Carlsbad, CA, USA); primerScript ${ }^{\mathrm{TM}} \mathrm{RT}$ reagent kit was purchased from TaKaRa (Dalian, China); power SYBR Green PCR Master Mix was purchased from Applied Biosystems (Carlsbad, CA, USA); phospho-STAT antibody sampler kit,
TABLE 1: Demographics of patients with OA from which synovial tissues were obtained from knee replacement surgeries.

\begin{tabular}{lcc}
\hline & \multicolumn{2}{c}{ OA } \\
& Female & Male \\
\hline Patient number & 6 & 4 \\
Age (years) & $64.5 \pm 3.7$ & $65.5 \pm 8.8$ \\
\hline
\end{tabular}

TABLE 2: Demographics of patients with OA and healthy controls from which blood samples were collected.

\begin{tabular}{lcc}
\hline & OA & HC \\
\hline Patient number & 30 & 30 \\
Gender (female/male) & $20 / 10$ & $20 / 10$ \\
Age (years) & $65.2 \pm 7.9$ & $43.2 \pm 8.7$ \\
\hline
\end{tabular}

phospho-c-Jun N-terminal kinases (JNK), phosphoextracellular signal-regulated kinases (ERK), phospho-p38, phosphoAKT, phospho-p65, phospho-I $\kappa \kappa \mathrm{B}$, and $\beta$-actin antibody were purchased from Cell Signaling Technology (Beverly, MA, USA); tissue culture reagents including Dulbecco's modified Eagle's medium (DMEM) and fetal bovine serum (FBS) were purchased from Gibco (Carlsbad, CA, USA).

2.2. Patients and Samples. Synovium and cartilage samples were harvested as surgical waste from 10 patients with endstage symptomatic knee $\mathrm{OA}$ at the time of surgery for total knee replacement. Blood samples were collected from $30 \mathrm{OA}$ patients and $30 \mathrm{HC}$. The general characteristics of both patients and controls subjects are summarized in Tables 1 and 2. OA diagnosis was determined by clinician assessment according to the American College of Rheumatology (ACR) criteria [6]. Usage of human tissues was approved by the Ethical Committee of the First Affiliated Hospital of Nanjing Medical University, and informed consent was obtained from all patients.

Blood samples were collected from peripheral veins and were processed within $1 \mathrm{~h}$ to provide serum for ELISA analysis and PBMC for RNA extract. Knee synovial tissues (5 OA and $3 \mathrm{HC}$ samples) were used for immunohistology analysis, and the remaining 5OA synovial samples were prepared for cell culture experiments.

2.3. Isolation and Culture of FLS. Primary OA FLS were isolated by enzymatic digestion of synovial tissues. In general, synovial tissue was minced and digested with $1 \%$ collagenase II at $37^{\circ} \mathrm{C}$ for $4 \mathrm{~h}$. OA FLS were cultured in DMEM medium supplemented with $10 \%$ fetal bovine serum (FBS), $100 \mathrm{U} / \mathrm{mL}$ penicillin, and $100 \mu \mathrm{g} / \mathrm{mL}$ streptomycin at $37^{\circ} \mathrm{C}$ in a humidified atmosphere of $5 \% \mathrm{CO}_{2}$ in air. Purity of OA FLS was determined by flow cytometry stained with antifibroblast marker (FGF-2). Cells were used for further experiments if $>95 \%$ cells were positive for fibroblast marker. Passages 2 to 5 cells were used in all experiments.

2.4. Flow Cytometry. IL-28R $\alpha$ expression on cell surface was measured using flow cytometric analysis. In brief, OA FLS 
TABLE 3: Human primers used for real-time quantitative PCR.

\begin{tabular}{lll}
\hline Gene symbol & Forward $\left(5^{\prime}-3^{\prime}\right)$ & Reverse $\left(5^{\prime}-3^{\prime}\right)$ \\
\hline IL-29 & GAAGCAGTTGCGATTTAGCC & GAAGCTCGCTAGCTCCTGTG \\
IL-28Ra & CCTCCCCAGAATGTGACGC & GGAGCCATGTCAGGTACACG \\
IL-1 $\beta$ & ATGATGGCTTATTACAGTGGCAA & ATGATGGCTTATTACAGTGGCAA \\
IL-6 & AACCTGAACCTTCCAAAGATGG & TCTGGCTTGTTCCTCACTACT \\
IL-8 & CATACTCCAAACCTTTCCACCCC \\
MMP-1 & GGCTGAAAGTGACTGGGAAACC & TCAGCCCTCTTCAAAAACTTCTCCA \\
MMP-2 & TACAGGATCATTGGCTACACACC & TGCTCTTGGCAAATCTGGCGTG \\
MMP-3 & CAGGCTTTCCCAAGCAAATA & GGTCACATCGCTCCAGACT \\
MMP-13 & ACTGAGAGGCTCCGAGAAATG & TTGCATTTGGGTCAAACTCC \\
TIMP-1 & GGGCTTCACCAAGACCTACA & GAACCCCGCATCTTGGCTT \\
GAPDH & AGAAGGCTGGGGCTCATTTG & TGCAGGGGATGGATAAACA \\
\hline
\end{tabular}

$\left(1 \times 10^{6}\right)$ were harvested, blocked with $1 \%$ bovine serum albumin (BSA) for $30 \mathrm{~min}$, and then stained with PE-conjugated IL-28R $\alpha$ for $25 \mathrm{~min}$ at room temperature in the dark. After washing 3 times with PBS, positive cells were determined using a BD FACSCalibur Flow Cytometer and CellQuest software (BD Biosciences).

2.5. MTT Assay. Cell viability was assessed by 3-(4,5-dimethylthiazol-2-yl)-2,5-diphenyltetrazolium bromide (MTT) assay following our published procedures [15]. Briefly, OA FLS $\left(5 \times 10^{3}\right)$ were incubated in a 96-well, flat-bottomed culture plate in a final volume of $200 \mu \mathrm{L} /$ well culture medium with IL-29 $(1,10$, and $100 \mathrm{ng} / \mathrm{mL})$ for $72 \mathrm{~h}$ in a humidified atmosphere $\left(37^{\circ} \mathrm{C}\right.$ at $\left.5 \% \mathrm{CO}_{2}\right)$. Next, $20 \mu \mathrm{L}$ of cell proliferation reagent WST-1 was added to each well and incubated for a further 4 hours. After incubation, the absorbance was measured at $450 \mathrm{~nm}$ using an ELISA plate reader (BioTek, Winooski, VT, USA).

2.6. Stimulation of FLS with IL-29. OA FLS were stimulated with IL-29 $(1,10$, and $100 \mathrm{ng} / \mathrm{mL})$ in the presence or absence of IL-29 blocking antibody (1000, 2000, and $3000 \mathrm{ng} / \mathrm{mL}$ ) for $48 \mathrm{~h}$. After incubation, cells were collected for gene expression analysis by real-time PCR. In another set, OA FLS were treated with $100 \mathrm{ng} / \mathrm{mL}$ IL-29 for $0 \mathrm{~min}, 20 \mathrm{~min}$, $40 \mathrm{~min}$, and $60 \mathrm{~min}$, respectively. After incubation, cells were collected for signaling pathway analysis by western blot.

2.7. Coculture of FLS with Ex Vivo Cartilage Explant. OA cartilages were obtained from knee joint tissue and submerged in a solution with betadine and PBS (1:3) for $10 \mathrm{~min}$ and then rinsed with $\mathrm{PBS}$ with no any trace of betadine. After freezethaw three times at $-80^{\circ} \mathrm{C}$ to kill any live cell within the tissue, cartilages were stored at $-20^{\circ} \mathrm{C}$ and ready for use.

OA FLS were cultured in 24-well plate until being $90 \%$ confluent and changed to fresh DMEM medium. Then, the cells were treated with IL-29 $(1,10$, and $100 \mathrm{ng} / \mathrm{mL})$ and IL$1 \beta$ (20 ng/mL, positive control). Thawed cartilage tissues were diced to similar size and placed to each well including OA FLS and IL-29. Cartilage, OA FLS, and IL-29 or IL- $1 \beta$ were coincubated in DMEM medium at $37^{\circ} \mathrm{C}$ in a humidified incubator ( $5 \% \mathrm{CO}_{2} /$ air). After $72 \mathrm{~h}$ incubation, cartilage tissues were removed from culture wells and fixed in $10 \%$ formalin. Cell supernatants were collected and stored at $-80^{\circ} \mathrm{C}$ for ELISA assay.

2.8. Real-Time PCR. Total RNA was extracted from PBMC and fibroblasts using TRIzol (Invitrogen). RNA was transcribed into cDNA in a $20 \mu \mathrm{L}$ mixture containing $1 \mu \mathrm{g}$ of total RNA and PrimeScript ${ }^{\mathrm{TM}}$ RT Master Mix (Takara) according to the manufacturer's instructions. Quantitative real-time PCR was performed on Applied Biosystems 7900 HT Instrument (Applied Biosystems, CA, USA) following our published procedures [7]. The primer sequences were summarized in Table 3. All samples were assayed in triplicate. Relative gene expression was determined by the $2^{-\Delta \Delta \mathrm{Ct}}$ method.

2.9. ELISA Assay. Human IL-29 and MMP-3 in serum or culture supernatants were measured by ELISA according to the manufacturer's instructions.

2.10. Immunohistochemistry and Safranin O-Fast Green Staining. Paraffin-embedded synovial tissues were sectioned, dewaxed, rehydrated, and stained following our published procedures [1]. The signals were developed with DAB substrate kit, with hematoxylin as counterstain. Each slide was evaluated by one of the authors under the microscopy (Nikon, Japan). Tissue sections were scored for staining of the lining on a 0 to 5 scale as reported [16]. For each section, the number of positively stained cells was counted in 20 fields. Scored data were pooled, and the mean \pm SEM was calculated.

Cartilage explants were embedded in paraffin wax. After sectioning and deparaffin, the slides were stained with the Safranin O staining kit to examine the cartilage loss according to the manufacturer's instructions. In brief, the slides were stained in $0.1 \%$ Fast Green solution for $10 \mathrm{~min}$, rinsed in $1 \%$ acetic acid for $15 \mathrm{sec}$, and stained in $0.1 \%$ Safranin $\mathrm{O}$ staining solution for $30 \mathrm{~min}$. After dehydration in ethanol and clearing in Xylene, the slides were mounted and observed under microscope (Nikon, Japan). Safranin binds to glycosaminoglycan (GAG) and shows an orange-red color. Cartilage depth 


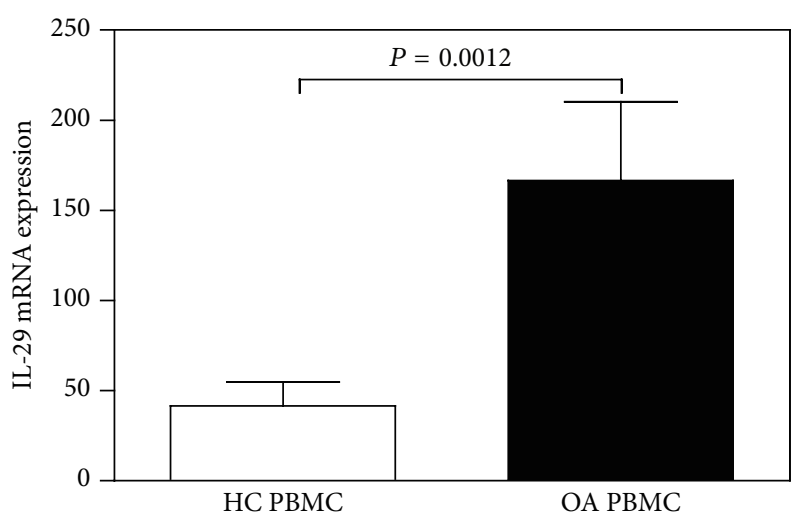

(a)

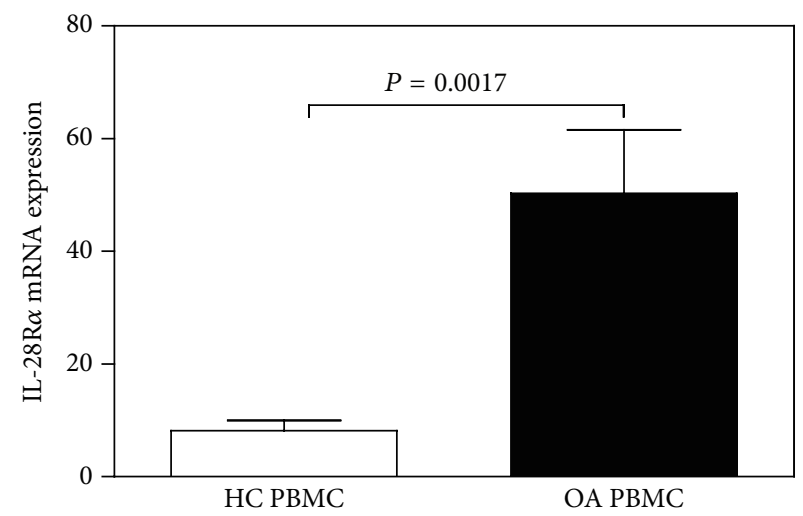

(b)

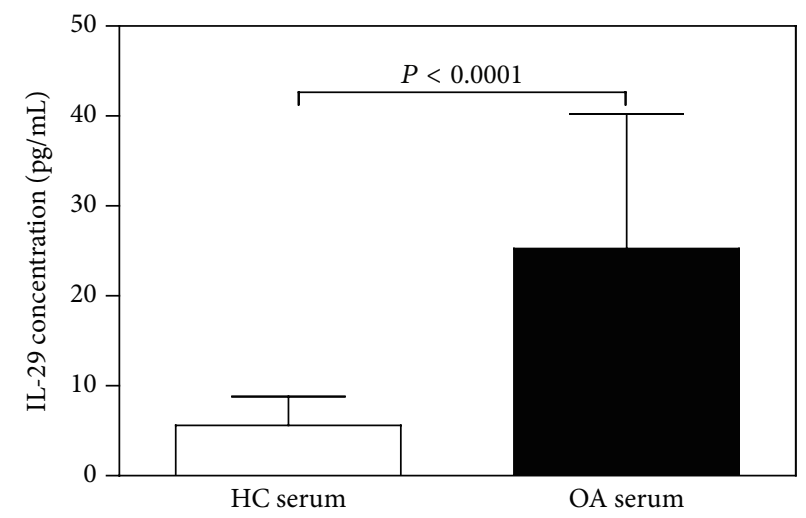

(c)

FIGURE 1: The expression of IL-29 and its receptor IL-28R $\alpha$ in the peripheral blood mononuclear cells (PBMCs) and serum of OA patients. The mRNA levels of IL-29 (a) and IL-28R $\alpha$ (b) in the OA PBMC $(n=30)$, when compared with that in HC PBMC $(n=30)$, were detected by real-time PCR. (c) The levels of IL-29 in the serum from OA patients $(n=30)$ and HC $(n=30)$ were assessed by ELISA. Data in graphs are the mean \pm SEM.

and GAG depletion were measured in $(\mu \mathrm{m}) 6$ random fields. Scored data were pooled, and the mean \pm SEM was calculated.

2.11. Immunofluorescence Staining. For cells immunofluorescence staining, OA FLS were seeded on cover slips and stained following our published procedures [1]. Briefly, OA FLS were fixed in $4 \%$ paraformaldehyde for $10 \mathrm{~min}$ and permeabilized with $0.3 \%$ Triton X-100 in PBS for 5 min. Then, the cells were incubated with anti-human IL-28R $\alpha$ antibody overnight at $4^{\circ} \mathrm{C}$. After washing, the cells were further incubated with goat anti-rabbit IgG/TRITC for $1 \mathrm{~h}$ in room temperature. Finally, the cells were washed and incubated with DAPI staining solution for 1-2 min and analyzed by fluorescence microscopy (Nikon, Japan). IL-28R $\alpha$ was stained in red and nuclei were stained in blue.

For tissue double immunofluorescence labeling, sections were incubated with a mixture of primary antibodies (rabbit anti-IL-29 pAb, mouse anti-CD68, or FGF-2 mAb) at $4^{\circ} \mathrm{C}$ overnight. After washing, the slides were further incubated with a mixture of donkey anti-rabbit IgG-R and DyLight488conjugated donkey anti-mouse IgG for $1 \mathrm{~h}$. Finally, the slides were washed and incubated with DAPI staining solution for 3-5 min. Images were acquired and processed digitally under the fluorescence microscopy (Olympus, Japan).
The contained positive cells were stained in yellow and nuclei were stained in blue.

2.12. Western Blot Assay. For western blotting assay, cellular proteins were resolved by $8 \%-10 \%$ sodium dodecyl sulfatepolyacrylamide gel electrophoresis (SDS-PAGE) and were transferred to polyvinylidene fluoride membranes (Millipore, Bedford, MA, USA). Nonspecific interactions were blocked with $5 \%$ skim milk for $2 \mathrm{~h}$ and were then probed with phospho-STAT 1/2/3/4/5/6, phospho-AKT, phospho-p38, phospho-ERK, phospho-JNK, phospho-p65, and phospho$\mathrm{I} \kappa \kappa \mathrm{B}$. $\beta$-actin was used as a protein loading control. The signals were visualized with Super Signal West Dura chemiluminescent detection reagents following the manufacturer's directions (Thermo Fisher Scientific Inc., Rockford, USA), and protein bands were scanned and quantified with the Gel-pro Analyzer software (Bio-Rad, CA, USA). The relative quantification of target proteins was calculated by comparison of the bands density levels between samples with Image J software.

2.13. Statistical Analysis. All data were expressed as mean \pm SEM and analyzed with Graphpad Prism 6 software (Graphpad software, La jolla, CA, USA). Differences between two 

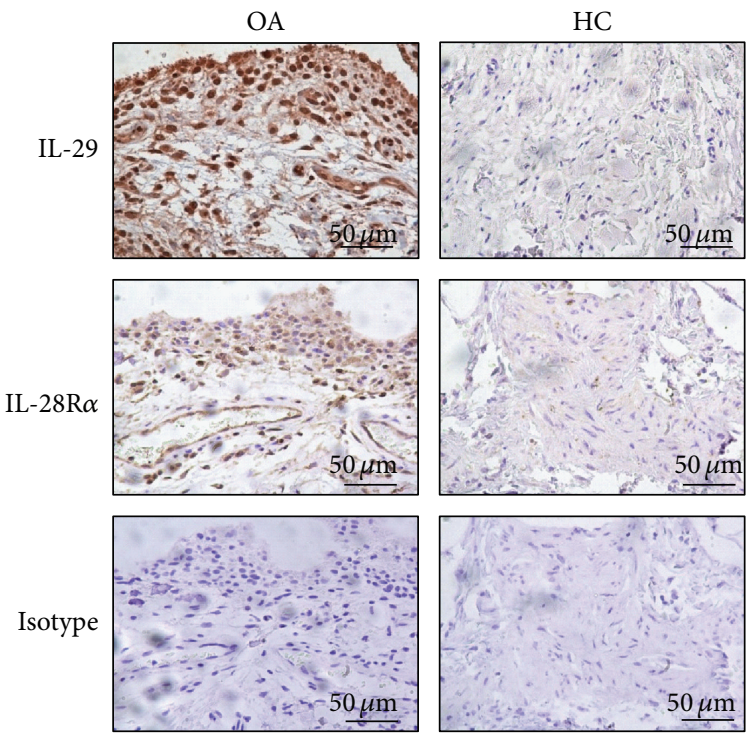

(a)
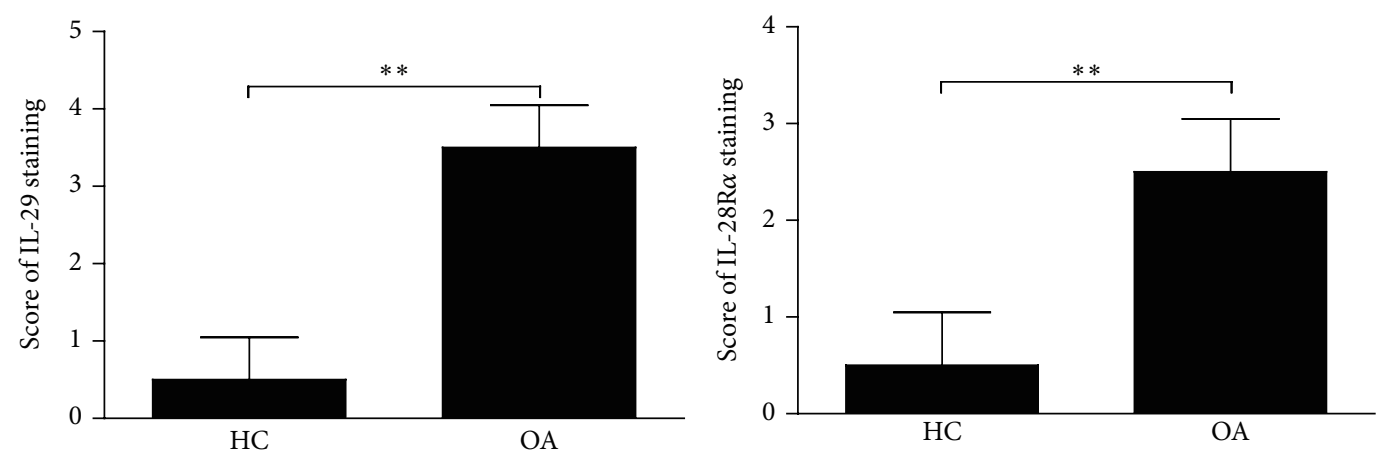

(b)
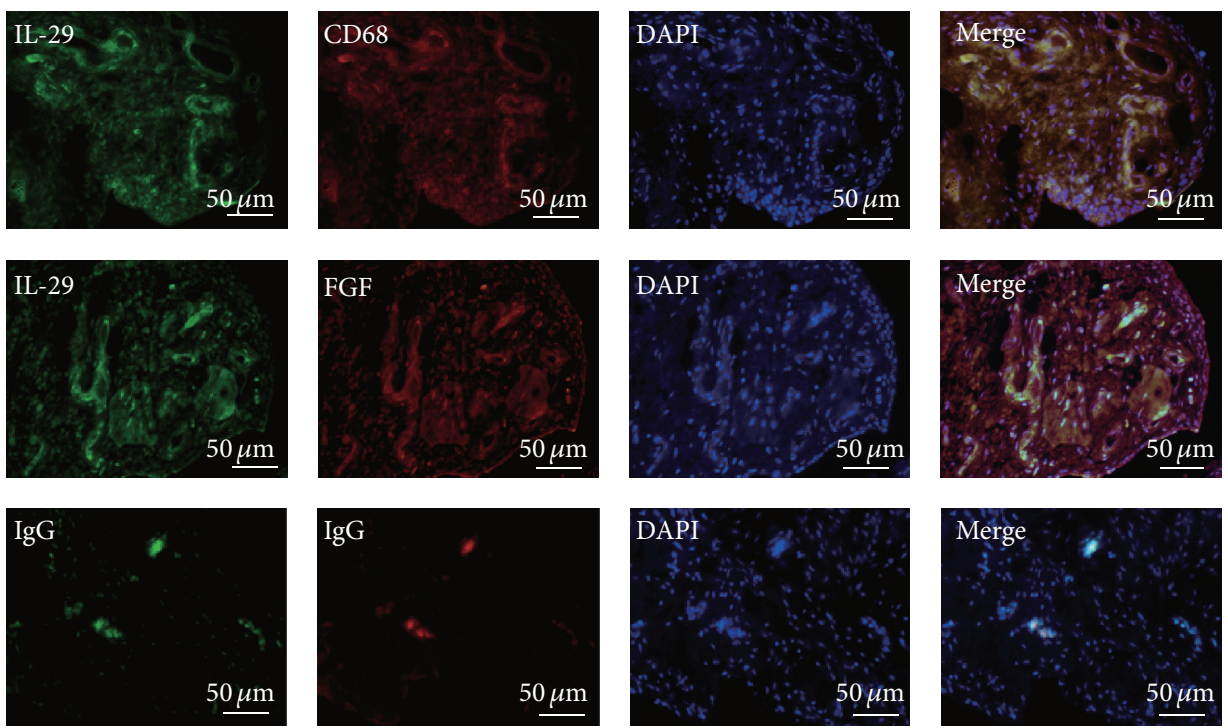

(c)

FIgURE 2: The expression and cellular distribution of IL-29 and IL-28R $\alpha$ in the synovial tissues. IL-29 and IL-28R $\alpha$ in synovial tissues of OA patients $(n=5)$ and HC $(n=3)$ were detected by immunostaining (a) and semiquantification (b). Values in (b) are the mean \pm SEM. ${ }^{* *} P<$ 0.01 versus medium control. (c) Colocalization of IL-29 with CD68 or FGF-2 in OA synovium was detected by double immunofluorescence staining, and nuclei were counterstained with DAPI. All of the magnification in this figure was $\times 400$. 

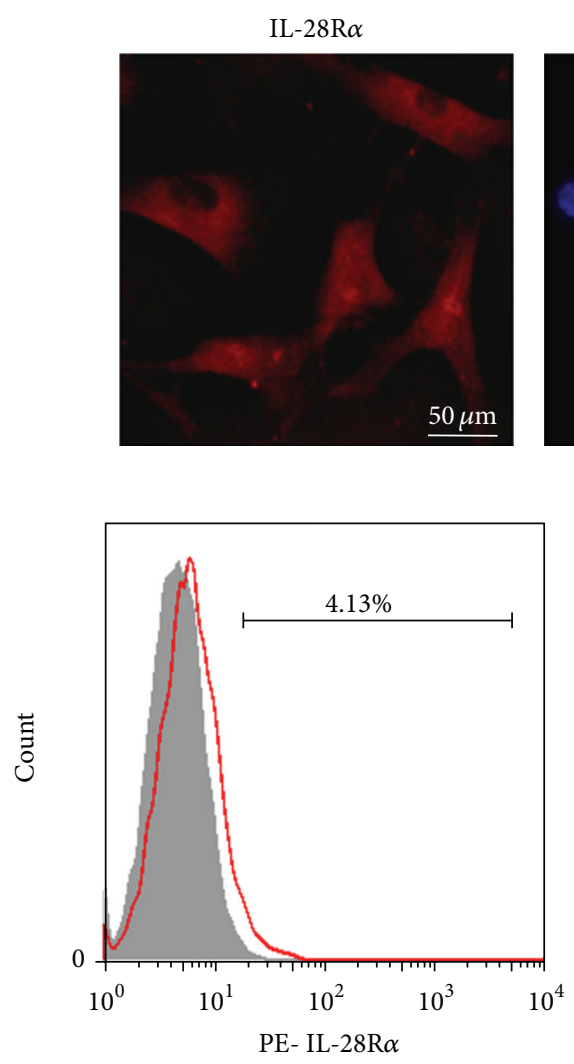

(b)
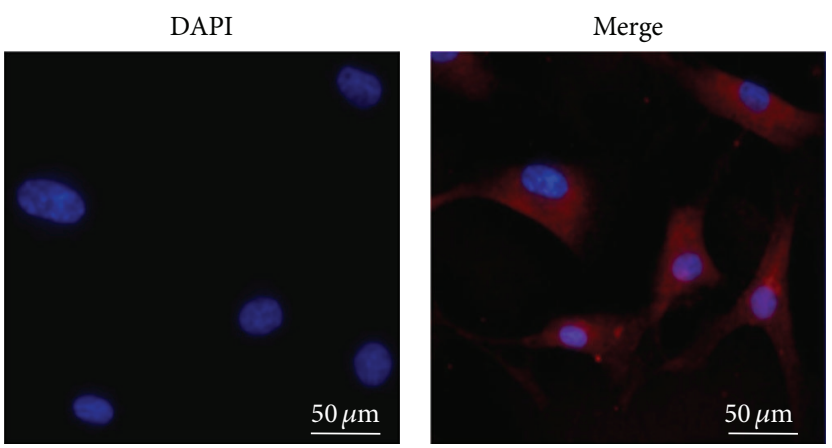

(a)

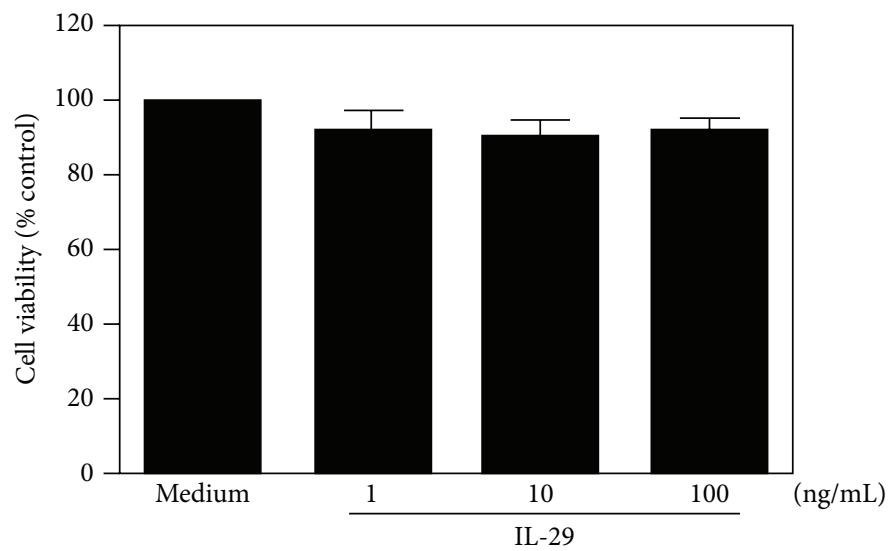

(c)

FIGURE 3: Immunostaining for IL-28R $\alpha$ in OA fibroblasts and viability of OA FLS in response to IL-29. The expression of IL-28R $\alpha$ in OA FLS, detected by immunofluorescent staining (a) and flow cytometric analysis (b). The magnification in (a) was $\times 400$. (c) OA FLS viability after being incubated with IL-29 at 1, 10, and $100 \mathrm{ng} / \mathrm{mL}$ for $72 \mathrm{~h}$ was measured by MTT assay. The data present the mean \pm SEM of three independent experiments.

groups were performed with Student's $t$-test for parametric data and Mann-Whitney $U$ test for nonparametric data. A $P$ value of $<0.05$ was considered significant.

\section{Results}

3.1. IL-29 and Its Receptor IL-28Ra Are Higher in PBMCs and Serum from OA Patients. To investigate whether IL-29 was involved in the pathogenesis of OA, we first examined the expression of IL-29 mRNA and its receptor IL-28Ra in PBMC. Real-time PCR analysis revealed that mRNA expression of IL-29 and IL-28Ra was significantly higher in OA PBMCs when compared to HC ( $P=0.0012$ and 0.0017 , resp.; Figures 1(a) and 1(b)).

In serum, ELISA analysis showed that IL-29 was significantly higher in OA $(25.26 \pm 3.34 \mathrm{pg} / \mathrm{mL})$ than in $\mathrm{HC}(5.61 \pm$ $0.71 \mathrm{pg} / \mathrm{mL}, P<0.0001$; Figure $1(\mathrm{c}))$.

3.2. Both IL-29 and IL-28Ra Expression Are Elevated in Synovial Tissue from OA Patients. Next, we assessed the expression and localization of IL-29 and IL-28Ra in synovial tissues from $5 \mathrm{OA}$ patients and $3 \mathrm{HC}$ with immunohistochemical analysis. As shown in Figure 2, IL-29 and IL-28Ra are strongly expressed in the lining layer of OA synovial tissues (Figure 2(a)), and semiquantitative analysis indicated that IL-29 and IL-28Ra were significantly increased in OA synovium compared to HC $(P=0.0045)$ (Figure 2(b)).

Because macrophages and FLS are the major effector cells for inflammation in the infiltrated OA synovium [4], we next examined whether macrophages and FLS can produce IL29 using double immunofluorescence staining. The specific antibodies against CD68 and FGF-2 served as markers for macrophages and fibroblasts, respectively. As shown in Figure 2(c), IL-29-positive cells were stained in red whereas CD68- or FGF-2-positive cells were stained in green, and positive cells for containing IL-29 with CD68 or FGF-2 were shown in yellow. As expected, IL-29 was strongly expressed in macrophages and fibroblasts in OA synovium, suggesting that these cells might be the important cellular sources of IL29 in OA synovium.

3.3. IL-29 Induces Proinflammatory Mediators in OA FLS. Immunofluorescence staining showed that IL-28Ra was expressed in OA FLS (Figures 3(a) and 3(b)), implying that OA FLS may be the important target of IL-29. IL-29 at 1, 10, and $100 \mathrm{ng} / \mathrm{mL}$ did not affect the viability of OA FLS after $72 \mathrm{~h}$ treatment (Figure 3(c)). Therefore, these doses were chosen for further experiments. 


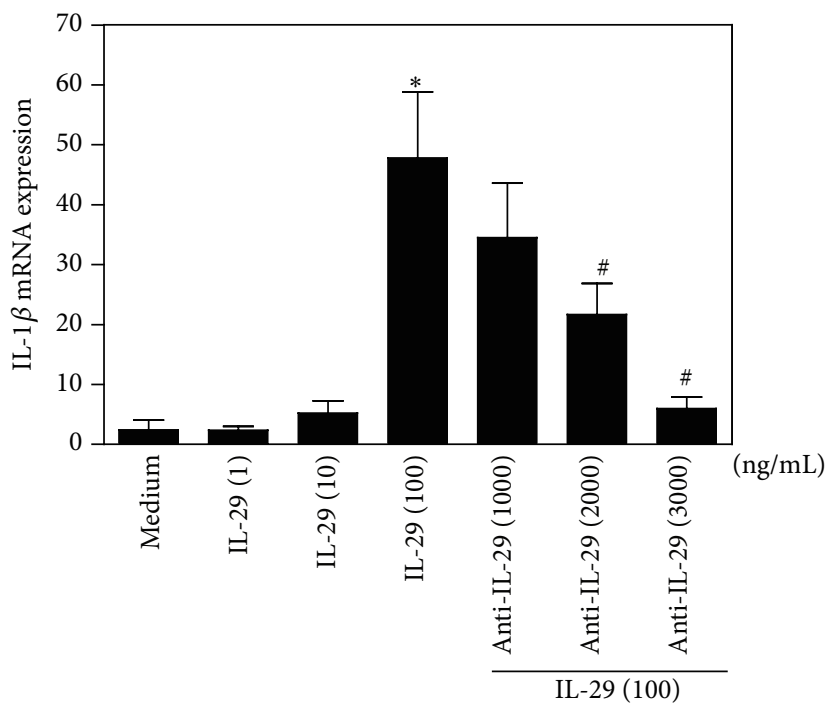

(a)

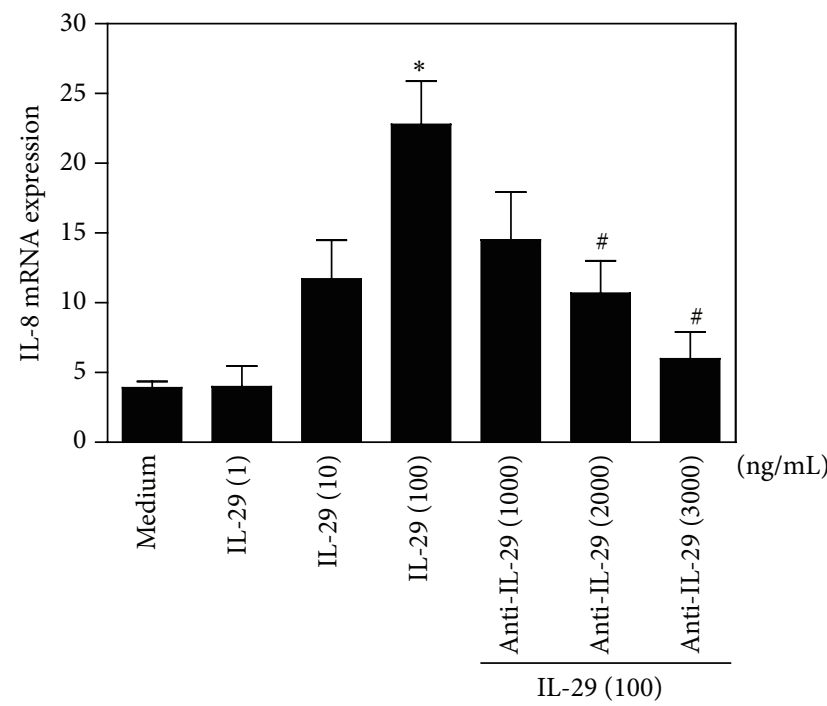

(c)

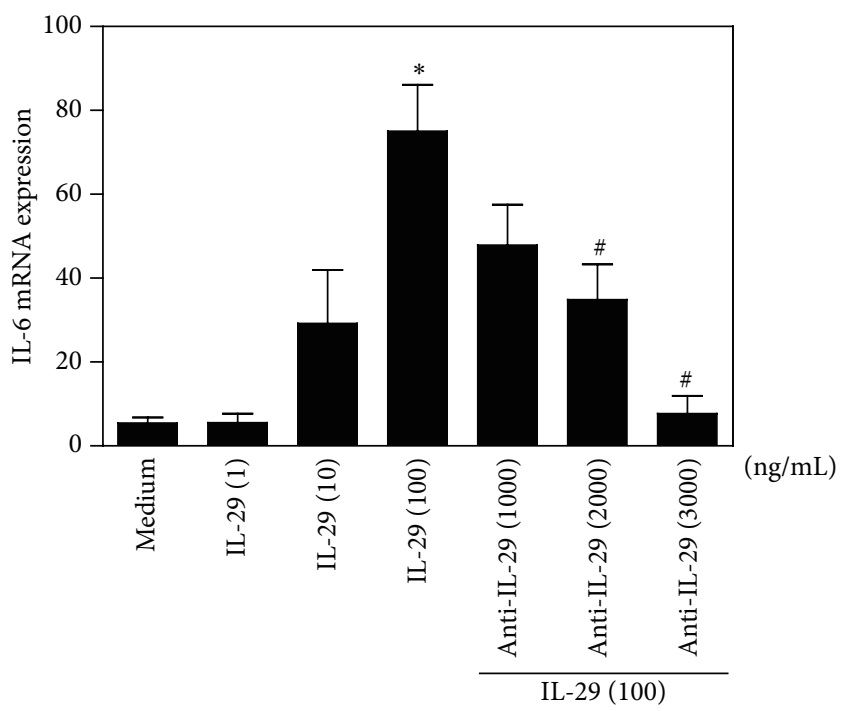

(b)

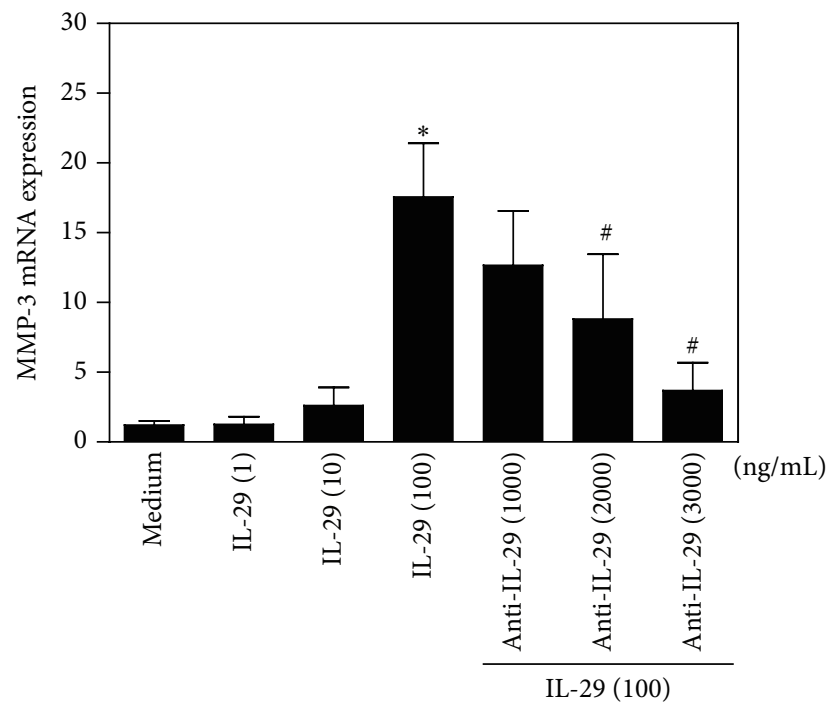

(d)

Figure 4: IL-29-induced cytokine expression by OA synovial fibroblasts. mRNA levels of IL-1 $\beta$ (a), IL-6 (b), IL-8 (c), and MMP-3 (d) in OA FLS after exposure to IL-29 (1, 10, and $100 \mathrm{ng} / \mathrm{mL})$ with or without its blocking antibody for $48 \mathrm{~h}$ were determined by real-time PCR. The results shown are representative of one of three independent experiments. The error bars represent mean \pm SEM for triplicate wells. ${ }^{*} P<0.05$ versus medium control. ${ }^{\#} P<0.05$ versus IL-29 $(100 \mathrm{ng} / \mathrm{mL})$ treatment group.

As shown in Figure 4, IL-29 induced a dose-dependent upregulation of IL- $1 \beta$, IL-6, IL-8, and MMP-3 mRNA in OA FLS following $48 \mathrm{~h}$ incubation. Furthermore, the action of IL29 on these cytokine expressions in OA FLS was abolished by addition of IL-29 blocking antibody at the concentration of 2000 and $3000 \mathrm{ng} / \mathrm{mL}$. These data indicate that IL-29 stimulates proinflammatory cytokine expression on OA FLS.

3.4. IL-29 Increases Cartilage Degradation. IL-29 can stimulate proinflammatory cytokines expression in OA FLS as shown in Figure 4, and chronic inflammation is a major driver of ongoing cartilage damage and joint degeneration in OA pathogenesis. Therefore, we chose a coculture model of OA FLS with ex vivo cartilage explant to examine the influence of IL-29 on cartilage degradation. After $72 \mathrm{~h}$ culture, Safranin O/Fast Green staining of the cartilage in the coculture showed that glycosaminoglycan (GAG) depletion (mean \pm SEM) was significantly greater in IL-29 $(100 \mathrm{ng} / \mathrm{mL})$ $(477.4 \pm 22.0 \mu \mathrm{m})$ or IL-1 $\beta(20 \mathrm{ng} / \mathrm{mL})(717.4 \pm 20.9 \mu \mathrm{m})$ treated conditions than that in the medium alone (154.4 \pm $7.1 \mu \mathrm{m}$ ), indicated by the less intense red staining for Safranin $\mathrm{O}$ and GAG depletion deeper (Figures 5(a) and 5(b)).

In $\mathrm{OA}$, cartilage damage is predominantly mediated by MMPs and its specific inhibitors, the tissue inhibitors of metalloproteinases family (TIMPs), most notably by MMP1, MMP-3, MMP-13, and TIMP-1 [14]. We examined the 


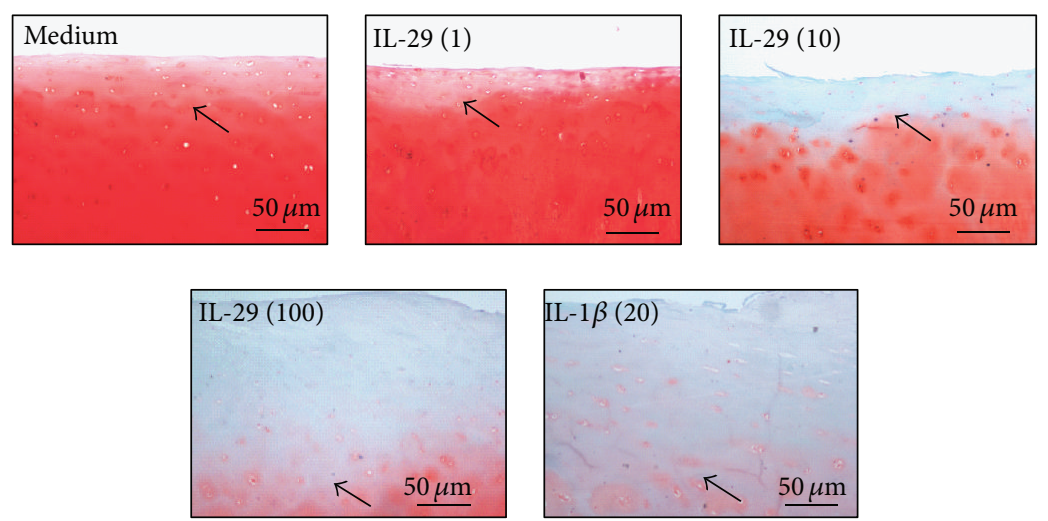

(a)

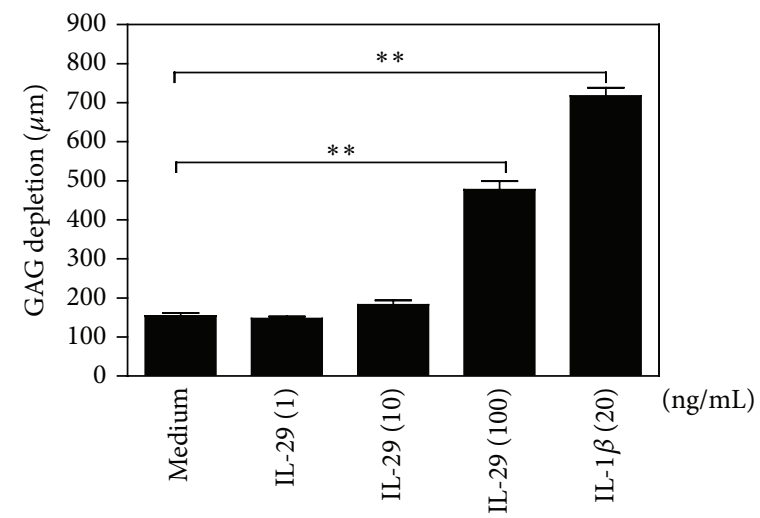

(b)
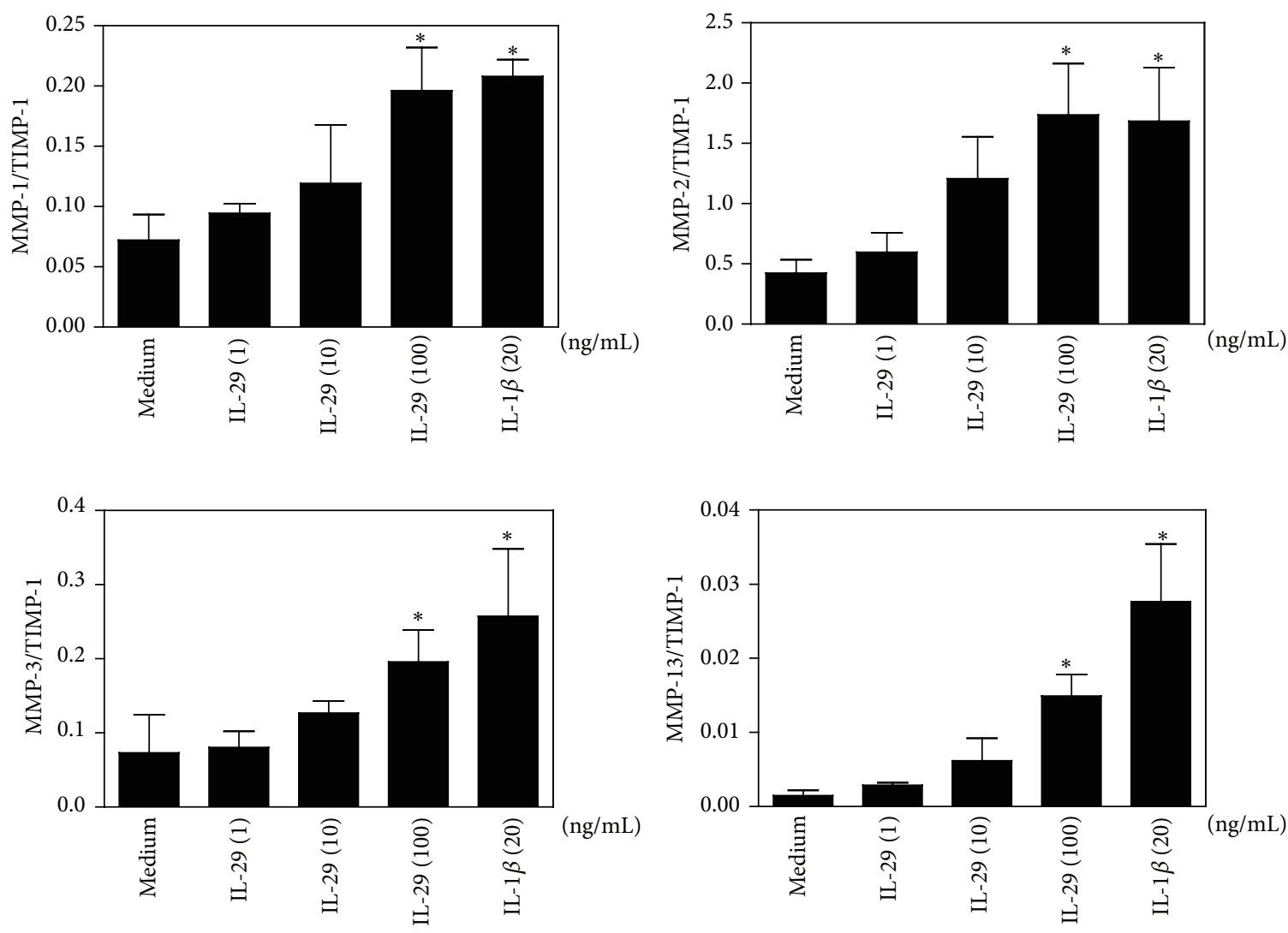

(c)

FIgure 5: Continued. 


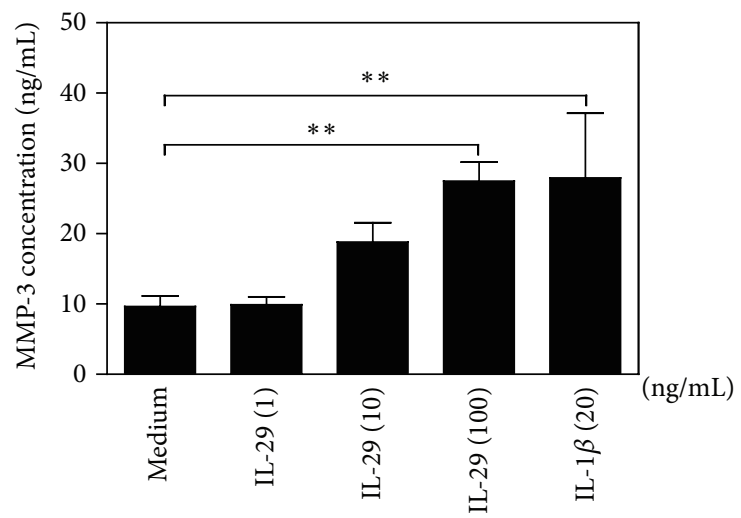

(d)

FIgURE 5: Effects of IL-29 on cartilage degradation by OA FLS ex vivo. (a) The OA cartilage depletion after being cocultured with OA FLS for $72 \mathrm{~h}$ was visualized in Safranin O/Fast Green-stained sections. Representative images from one experiment are reported (a), and the reduced intensity of red stain denotes proteoglycan loss (original magnification $\times 100$ ). (b) The depth of GAG depletion $(\mu \mathrm{m})$ in cartilage was measured from the articular surface to the red/orange tidemark (marked by arrow). (c) The ratio of MM-1, MM-2, MM-3, and MM-13 to TIMP-1 was determined by real-time PCR in OA FLS. (d) MMP-3 in culture supernatants harvested from each well after $72 \mathrm{~h}$ was measured by ELISA. The error bars represent mean \pm SEM for triplicate experiments. ${ }^{*} P<0.05$ versus medium control. ${ }^{* *} P<0.01$ versus medium control.

ratio of MMP-1, MMP-2, MMP-3, and MMP-13 to TIMP1 in the OA FLS after $72 \mathrm{~h}$ coculture and found that IL29 could significantly upregulate MMP-1/TIMP-1, MMP2/TIMP-1, MMP-3/TIMP-1, and MMP-13/TIMP-1 ratio at a dose-dependent manner in OA FLS. We also measured MMP-3 levels in supernatant at $72 \mathrm{~h}$ incubation in this experiment. Consistent with our finding in OA FLS monocultures, there were higher levels of MMP-3 in OA FLS/cartilage coculture system in response to IL-29 at $100 \mathrm{ng} / \mathrm{mL}$ when compared to nontreatment control (Figure 5(c)), similar to that stimulated by IL- $\beta(20 \mathrm{ng} / \mathrm{mL})$. These data imply that IL-29 promotes cartilage degradation by stimulating protease production in OA FLS.

3.5. IL-29 Induces Signal Transduction in OA FLS. OA FLS were stimulated with IL-29 and the activation of downstream signal transduction pathways including canonical Jak-STAT and noncanonical MAPK, AKT, and NF- $\kappa$ B pathways was evaluated (Figure 6). Following stimulation of OA FLS for $20 \mathrm{~min}, 40 \mathrm{~min}$, and $60 \mathrm{~min}$ with IL-29 $(100 \mathrm{ng} / \mathrm{mL})$, phosphorylation of STAT 1 (Tyr701) and STAT 5 (Tyr694); JNK, ERK, and P38; and P65 and I $\kappa \kappa \mathrm{B}$ was significantly increased when compared to nontreatment controls. No change in phosphorylation of STATs 2 (Tyr690), 3 (Tyr705), and 6 (Tyr641) and AKT was observed in response to IL-29. Phosphorylation of STAT 3 (Ser727) and STAT 4 (Tyr693) was not detectable in OA FLS.

\section{Discussion}

OA has traditionally been classified as a noninflammatory arthritis; however, the accumulating evidences demonstrate that joint inflammation and synovitis play a critical role in the pathogenesis of OA. Our study for the first time showed that IL-29, a novel member of type III interferon family, (i) was upregulated in blood and synovial tissues in patients with OA; (ii) enhanced inflammation of OA FLS and promoted cartilage degradation; and (iii) activated MAPK and $\mathrm{NF}-\kappa \mathrm{B}$ signaling pathway.

In the first case, we demonstrate an essential role of IL29 in inflammation in OA FLS. We found that IL-29 was abnormally elevated in PBMC, serum, synovial fluid, and synovium in OA patients. Within the joint, IL-29 and its receptor were located at FLS and macrophages, two main cell types in the inflamed synovium responsible for the inflammation and cartilage and bone damage in the joint. Abnormal IL-29 was also found in RA [1], SLE [11], gastric cancer [17], or other diseases. Similar to RA, in this study, we did not find a significant correlation between IL-29 in serum and OA disease activity (data not shown). The lack of a significant association may be due to the limited sample size and most of the patients having end-stage symptom of knee OA. Thus, further prospective studies including a larger sample size and OA patients in early and late disease are needed to determine whether IL-29 can serve as a biomarker for systemic inflammation and OA disease activity.

We have reported that IL-29 contributed to synovial inflammation by stimulating production of proinflammatory cytokines in RA FLS [1]. The proinflammatory effects of IL-29 have also been shown on PBMC by upregulation of IFN-inducible protein-10 (IP-10), monokine induced by IFN- $\gamma$ (MIG), IFN- $\gamma$-inducible T cell $\alpha$ chemoattractant (ITAC/CXCL11), and IL- $8[11,18]$ and on T cells by downregulating Th2 polarization and cytokine production $[15,19,20]$. Soluble inflammatory factors such as cytokines are central to most inflammatory processes, and several cytokines have been implicated in OA pathogenesis including IL-6 and IL8 , TNF- $\alpha$, and IL- $1 \beta$. Indeed, our data showed that IL-29 stimulated inflammatory cytokines IL- $1 \beta$, IL- 6 , and IL- 8 and production in OA FLS, indicating that IL-29 may contribute to OA inflammation. 


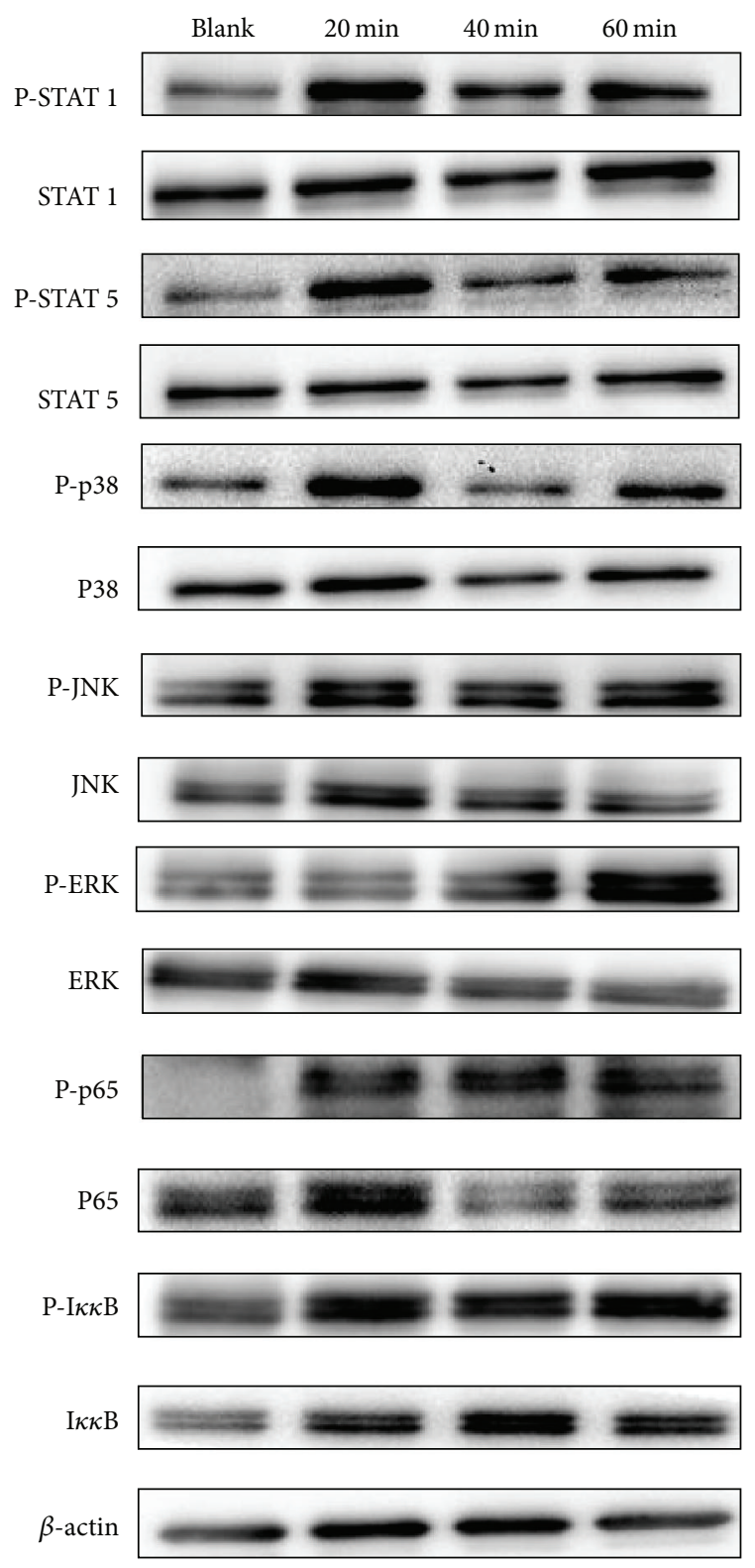

(a)

P-STAT 1

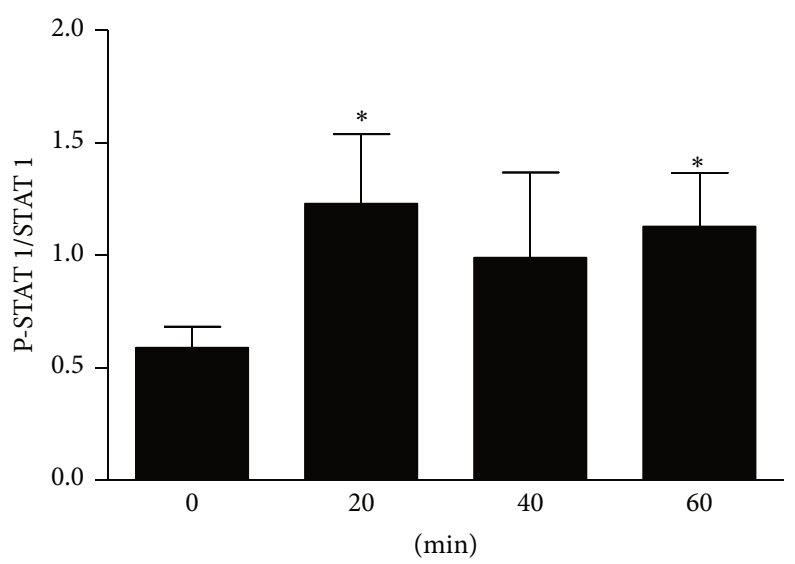

P-STAT 5

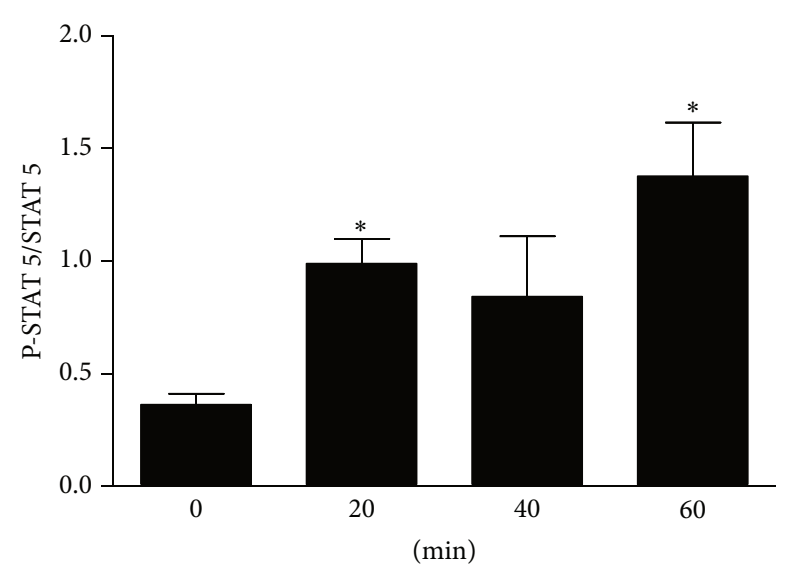

FIgURE 6: Continued. 

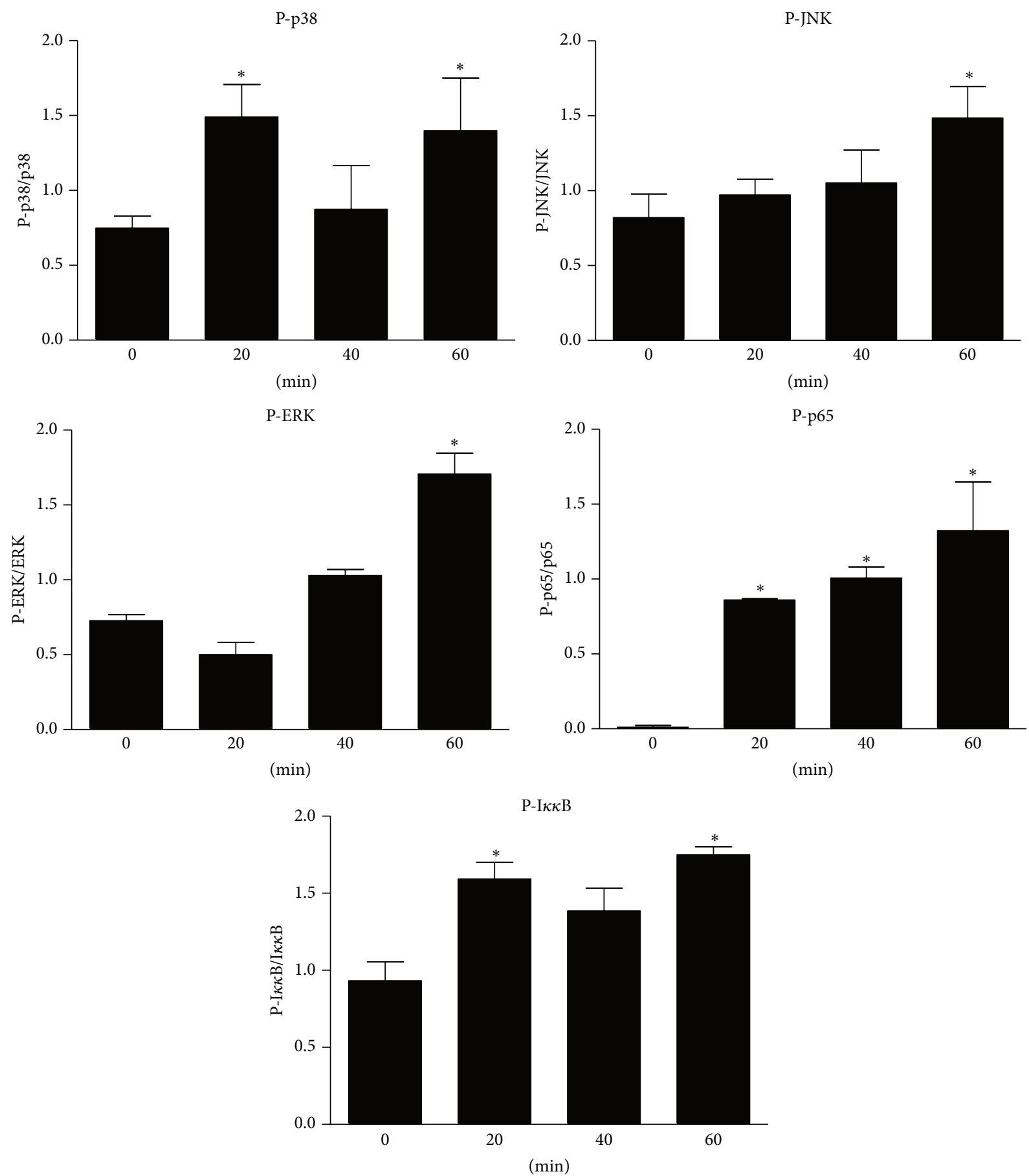

(b)

FIGURE 6: Effect of IL-29 on the phosphorylation of Jak-STAT, AKT, MAPK, and NF- $\kappa$ B signaling pathways. OA FLS were treated with IL-29 at $100 \mathrm{ng} / \mathrm{mL}$ for $0,20,40$, and $60 \mathrm{~min}$, and the activation of STAT 1/2/3/4/5/6, AKT, JNK, ERK, P38, p65, and NF- $\kappa$ B was evaluated by western blot. The relative quantification of target proteins was calculated by comparison of the bands density levels between samples. The results were expressed as mean \pm SEM from three independent experiments. ${ }^{*} \mathrm{P}<0.05$ versus nontreatment group.

Recent epidemiological studies on large number of OA patients suggested that an inflammatory synovium/synovitis was linked to increased cartilage damage and pain [21]. FLS, the major cellular constituent of the synovial membrane, are the main contributors to the inflammation and cartilage degrading MMP overproduction within the arthritic joint $[11,12,22]$. Proinflammatory cytokines derived from FLS including IL- 6 and IL- 8 , TNF- $\alpha$, and IL- $1 \beta$ could increase the production of MMPs leading to cartilage damage. Our data also showed that MMP-3 mRNA was significantly increased 
in FLS upon IL-29 treatment; hence, we further address the interaction between IL-29, inflammation, MMP production, and cartilage degradation.

The second novel finding of this study is that IL-29 plays a critical role in cartilage degradation in OA. We used a coculture system to establish a direct link between IL-29 and cartilage degradation. In this model, FLS were cultured with OA cartilage explant to model inflammation-induced MMP production and cartilage degradation. Our data showed that IL-29 enhanced MMPs/TIMP-1 ratio in OA FLS and then resulted in marked increased GAG depletion in cartilage. Taken together, our data suggest an important role for IL29 in regulating cartilage degradation by driving cytokine and MMP production in OA FLS. IL-29 is thus capable of modulating one of the most important processes driving tissue degeneration in OA pathogenesis.

It has been suggested that IL-29 elicits signal transduction via activation of the canonical Jak-STAT pathway and other alternative pathways including AKT and the mitogenactivated protein kinase (MAPK) in a panel of cells [2325]. However, the ability of IL-29 to trigger the pathways could be cell-type specific or altered in cells. The present study is the first to report the signal transduction pathways in response to IL-29 in OA FLS. In these cells, IL-29 stimulated the phosphorylation of STATs 1 and 5. Phosphorylated STATs form various homodimers and heterodimers, translocate to the nucleus, and induced IL-29-specific biological activities, such as antiviral protection, antiproliferative response, and antitumor activities [26]. And the most prominent biological function of IL-29 resides in their ability to induce antiviral state in cells; thus, the canonical Jak-STAT signal pathway is the major pathway involved in IL-29-induced antiviral action, whereas the effect of IL-29 on proinflammatory cytokines production in OA FLS may be one key point for studying OA pathogenesis. It is therefore hypothesized that alternative signaling pathways could be more important in OA FLS after IL-29 stimulation. Indeed, IL-29 induced strong NF- $\kappa$ B and MAPK (P-JNK, P-ERK, and P38) signal transduction in OA FLS. However, whether these pathways are involved in IL29 mediated effects on OA FLS has to be investigated in the further study with the inhibitors of these pathways. Recent studies suggested that inhibitors of the above two pathways have received more attention in animal model studies and clinical trials in OA patients [12].

Collectively, our present data combined with these reports suggested that IL-29-mediated inflammation was the pivotal function of IL-29 in OA pathogenesis and inhibition of IL-29 would be a potential therapeutic target in OA disease.

\section{Conclusions}

In summary, this study provides the first evidence that IL29 is dysregulated in OA patients and may contribute to synovial inflammation and cartilage degeneration during $\mathrm{OA}$ pathogenesis by production of proinflammatory cytokine. Further studies of the immunoregulatory effects of IL-29 and its underlying molecular mechanism are warranted to understand the pathological role of IL-29 in OA disease.

\section{Abbreviations}

$\begin{array}{ll}\text { OA: } & \text { Osteoarthritis } \\ \text { HC: } & \text { Healthy controls } \\ \text { IL-29: } & \text { Interleukin-29 } \\ \text { FLS: } & \text { Synovial fibroblasts } \\ \text { PBMCs: } & \text { Peripheral blood mononuclear cells } \\ \text { MMP-3: } & \text { Matrix-metalloproteinase-3 } \\ \text { IFNs: } & \text { Interferons } \\ \text { rhIL-29: } & \text { Recombinant human IL-29 } \\ \text { DAPI: } & \text { 40,6-Diamidine-20-phenylindole } \\ & \text { dihydrochloride. }\end{array}$

\section{Competing Interests}

The authors declare that they have no competing interests regarding the publication of this paper.

\section{Authors' Contributions}

Fang Wang and Meilang Xue contributed to the study design, data analysis, and interpretation and the paper draft and edition. Lingxiao Xu and Qiuyue Peng carried out the cell culture. Wenhua Xuan and Xiangqing Kong participated in the immunoassays. Xiangqing Kong, Miaojia Zhang, and Wenfeng Tan conceived the study and participated in its design and coordination and helped to draft the paper. Dr. Lingxiao $\mathrm{Xu}$ and Qiuyue Peng contributed equally to this work.

\section{Acknowledgments}

This project was sponsored by the grants from the National Natural Science Foundation of China (nos. 81471610, 81471611, 81401352, 81172845, and bk20141021) and the Priority Academic Program Development of Jiangsu Higher Education Institutions (PAPD). Dr. Xiangqing Kong is a Fellow at the Collaborative Innovation Center for Cardiovascular Disease Translational Medicine.

\section{References}

[1] F. Wang, L. Xu, X. Feng, D. Guo, W. Tan, and M. Zhang, "Interleukin-29 modulates proinflammatory cytokine production in synovial inflammation of rheumatoid arthritis," Arthritis Research and Therapy, vol. 14, no. 5, article R228, 2012.

[2] L. Xu, X. Feng, W. Tan et al., "IL-29 enhances Toll-like receptormediated IL- 6 and IL- 8 production by the synovial fibroblasts from rheumatoid arthritis patients," Arthritis Research \& Therapy, vol. 15, no. 5, article R170, 2013.

[3] N. J. Megjugorac, G. E. Gallagher, and G. Gallagher, "Modulation of human plasmacytoid DC function by IFN- $\lambda 1$ (IL-29)," Journal of Leukocyte Biology, vol. 86, no. 6, pp. 1359-1363, 2009.

[4] B.-S. Liu, H. L. A. Janssen, and A. Boonstra, "IL-29 and IFN $\alpha$ differ in their ability to modulate IL- 12 production by TLR-activated human macrophages and exhibit differential regulation of the IFN $\gamma$ receptor expression," Blood, vol. 117, no. 8, pp. 2385-2395, 2011.

[5] K. Wolk, K. Witte, E. Witte et al., "IL-29 is produced by $\mathrm{T}(\mathrm{H}) 17$ cells and mediates the cutaneous antiviral competence 
in psoriasis," Science Translational Medicine, vol. 5, no. 204, Article ID 204ra129, 2013.

[6] R. A. de Groen, A. Boltjes, J. Hou et al., "IFN- $\lambda$-mediated IL12 production in macrophages induces IFN- $\gamma$ production in human NK cells," European Journal of Immunology, vol. 45, no. 1, pp. 250-259, 2015.

[7] S. V. Kotenko, "IFN-lambdas," Current Opinion in Immunology, vol. 23, no. 5, pp. 583-590, 2011.

[8] M. Li, X. Liu, Y. Zhou, and B. S. Shao, "Interferon- $\lambda$ s: the modulators of antivirus, antitumor, and immune responses," Journal of Leukocyte Biology, vol. 86, no. 1, pp. 23-32, 2009.

[9] W. Abushahba, M. Balan, I. Castaneda et al., "Antitumor activity of Type i and Type III interferons in BNL hepatoma model," Cancer Immunology, Immunotherapy, vol. 59, no. 7, pp. 10591071, 2010.

[10] S. He, H. Zhang, H. Chen et al., "Expression and release of IL29 by mast cells and modulation of mast cell behavior by IL-29," Allergy, vol. 65, no. 10, pp. 1234-1241, 2010.

[11] Q. Wu, Q. Yang, E. Lourenco, H. Sun, and Y. Zhang, "Interferonlambdal induces peripheral blood mononuclear cell-derived chemokines secretion in patients with systemic lupus erythematosus: Its correlation with disease activity," Arthritis Research and Therapy, vol. 13, no. 3, article R88, 2011.

[12] S.-C. Lin, C.-C. Kuo, J.-T. Tsao, and L.-J. Lin, "Profiling the expression of interleukin (IL)-28 and IL-28 receptor $\alpha$ in systemic lupus erythematosus patients," European Journal of Clinical Investigation, vol. 42, no. 1, pp. 61-69, 2012.

[13] M. M. C. Steenvoorden, R. A. Bank, H. K. Ronday, R. E. M. Toes, T. W. J. Huizinga, and J. DeGroot, "Fibroblast-like synoviocytechondrocyte interaction in cartilage degradation," Clinical and Experimental Rheumatology, vol. 25, no. 2, pp. 239-245, 2007.

[14] A. Nair, V. Kanda, C. Bush-Joseph et al., "Synovial fluid from patients with early osteoarthritis modulates fibroblastlike synoviocyte responses to toll-like receptor 4 and toll-like receptor 2 ligands via soluble CD14," Arthritis \& Rheumatism, vol. 64, no. 7, pp. 2268-2277, 2012.

[15] W. J. Jordan, J. Eskdale, M. Boniotto, M. Rodia, D. Kellner, and G. Gallagher, "Modulation of the human cytokine response by interferon lambda-1 (IFN-入1/IL-29)," Genes and Immunity, vol. 8, no. 1, pp. 13-20, 2007.

[16] S. R. Pickens, N. D. Chamberlain, M. V. Volin, R. M. Pope, A. M. Mandelin II, and S. Shahrara, "Characterization of CCL19 and CCL21 in rheumatoid arthritis," Arthritis \& Rheumatism, vol. 63, no. 4, pp. 914-922, 2011.

[17] K. Erturk, D. Tastekin, M. Serilmez, E. Bilgin, H. U. Bozbey, and S. Vatansever, "Clinical significance of serum interleukin29, interleukin-32, and tumor necrosis factor alpha levels in patients with gastric cancer," Tumor Biology, vol. 37, no. 1, pp. 405-412, 2016.

[18] V. Pekarek, S. Srinivas, J. EskdaleJ, and G. Gallagher, "Interferon lambda-1 (IFN-lambda1/IL-29) induces ELR(-) CXC chemokine mRNA in human peripheral blood mononuclear cells, in an IFN-gamma-independent manner," Genes and Immunity, vol. 8, no. 2, pp. 177-180, 2007.

[19] W. J. Jordan, J. Eskdale, S. Srinivas et al., "Human interferon lambda-1 (IFN- $\lambda 1 /$ IL-29) modulates the Th1/Th2 response," Genes and Immunity, vol. 8, no. 3, pp. 254-261, 2007.

[20] J. Dai, N. J. Megjugorac, G. E. Gallagher, R. Y. L. Yu, and G. Gallagher, "IFN- $\lambda 1$ (IL-29) inhibits GATA3 expression and suppresses Th2 responses in human naive and memory T cells," Blood, vol. 113, no. 23, pp. 5829-5838, 2009.
[21] A. Haseeb and T. M. Haqqi, "Immunopathogenesis of osteoarthritis," Clinical Immunology, vol. 146, no. 3, pp. 185-196, 2013.

[22] S. He, T. Li, H. Chen et al., "CD14+ cell-derived IL-29 modulates proinflammatory cytokine production in patients with allergic airway inflammation," Allergy: European Journal of Allergy and Clinical Immunology, vol. 66, no. 2, pp. 238-246, 2011.

[23] S. Brand, F. Beigel, T. Olszak et al., "IL-28A and IL-29 mediate antiproliferative and antiviral signals in intestinal epithelial cells and murine CMV infection increases colonic IL-28A expression," American Journal of Physiology-Gastrointestinal and Liver Physiology, vol. 289, no. 5, pp. G960-G968, 2005.

[24] Z. Zhou, O. J. Hamming, N. Ank, S. R. Paludan, A. L. Nielsen, and R. Hartmann, "Type III interferon (IFN) induces a type I IFN-like response in a restricted subset of cells through signaling pathways involving both the Jak-STAT pathway and the mitogen-activated protein kinases," Journal of Virology, vol. 81, no. 14, pp. 7749-7758, 2007.

[25] K. D. Guenterberg, V. P. Grignol, E. T. Raig et al., "Interleukin-29 binds to melanoma cells inducing Jak-STAT signal transduction and apoptosis," Molecular Cancer Therapeutics, vol. 9, no. 2, pp. 510-520, 2010.

[26] L. Dumoutier, A. Tounsi, T. Michiels, C. Sommereyns, S. V. Kotenko, and J. C. Renauld, "Role of the interleukin (IL)-28 receptor tyrosine residues for antiviral and antiproliferative activity of IL-29/interferon-lambda 1: similarities with type I interferon signaling," The Journal of Biological Chemistry, vol. 279, no. 31, pp. 32269-32274, 2004. 


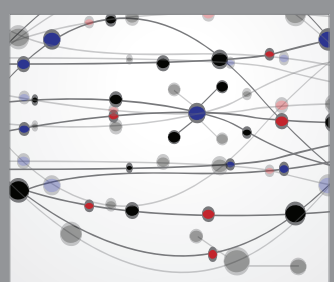

The Scientific World Journal
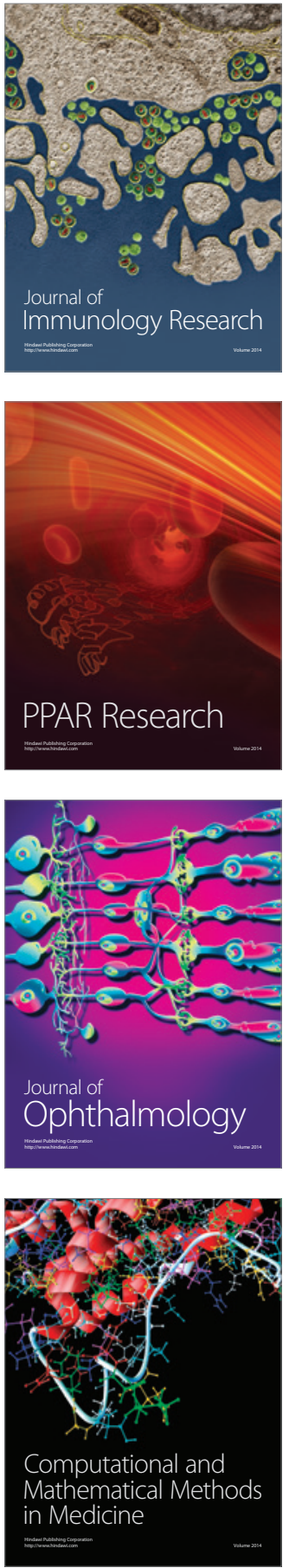

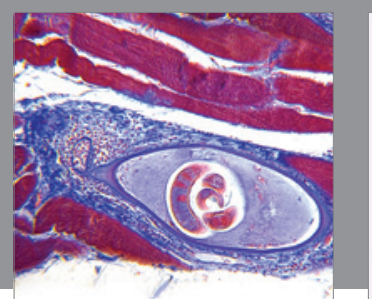

Gastroenterology Research and Practice

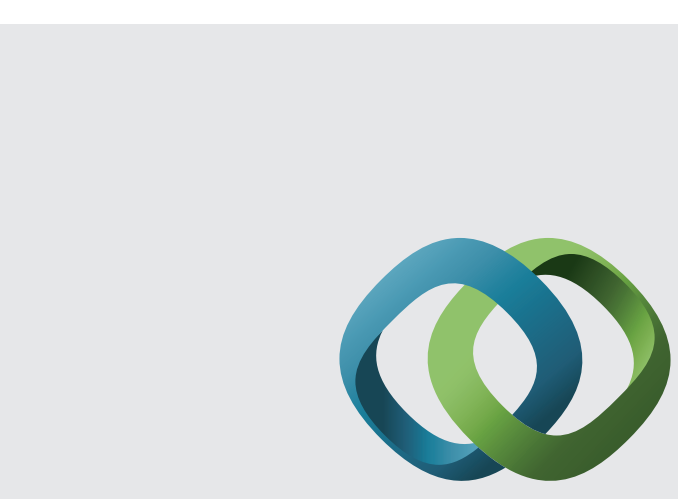

\section{Hindawi}

Submit your manuscripts at

http://www.hindawi.com
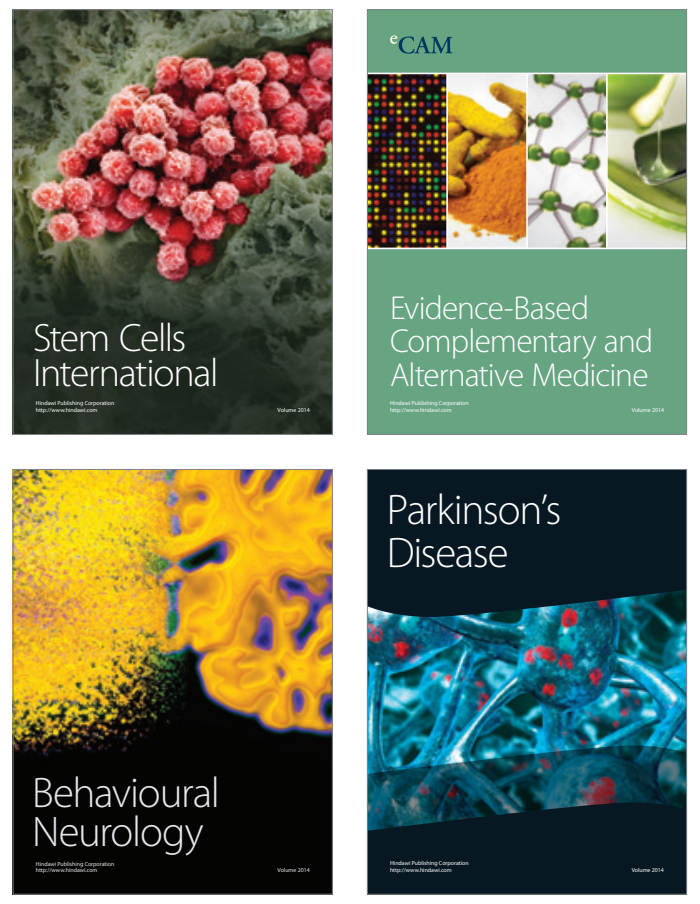
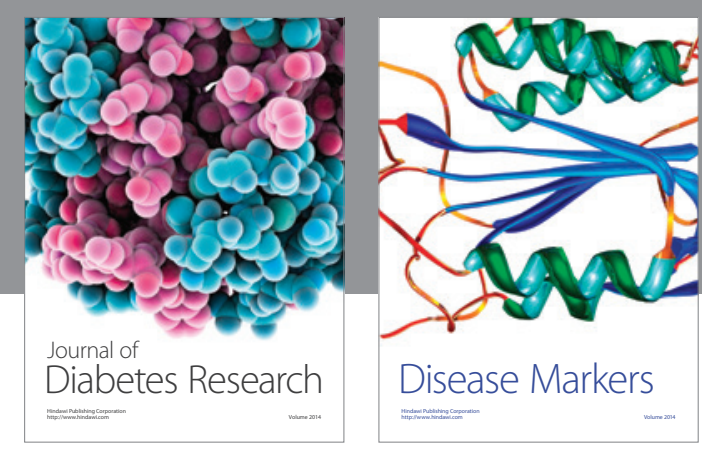

Disease Markers
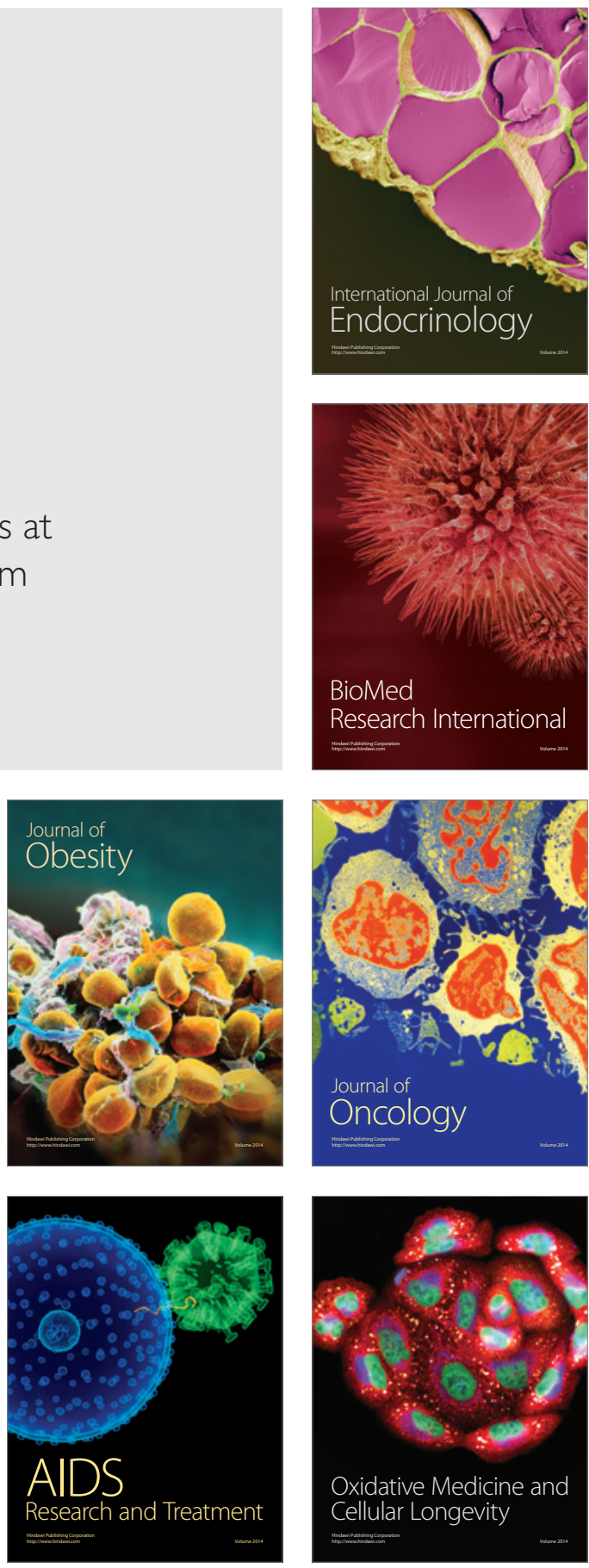